\title{
As várias faces da moeda: representações da responsabilidade social em um banco brasileiro $^{1}$
}

The different sides of the same coin: representations of social responsibility in a Brazilian bank

Las varias caras de la moneda: representaciones de la responsabilidad social en un banco brasilero

\section{Luíza Mônica Assis da Silva}

- Doutora em Psicologia Social, do Trabalho e das Organizações pela Universidade de Brasília (UnB)

- Professora do Mestrado em Comunicação da Universidade Católica de Brasília (UCB)

- E-mail: luiza@ucb.br

\section{Ana Lúcia Galinkin}

- Doutora em Sociologia pela Universidade de São Paulo (USP)

- Professora Associada III do Programa de Pós-Graduação em Psicologia Social, do Trabalho e das Organizações, do Instituto de Psicologia da UnB

- Atua nos temas: gênero, violência; minorias, movimentos e mudanças sociais

- E-mail: anagalinkin@gmail.com

\section{Angela Maria de Oliveira Almeida}

- Doutora em Psicologia pela Université Catholique de Louvain

- Professora associada do Programa de Pós-Graduação em Psicologia Social, do Trabalho e das Organizações, do Instituto de Psicologia da UnB

- Dirige o Centro Internacional de Pesquisa em Representações e Psicologia Social "Serge Moscovici"

- E-mail: aalmeida@unb.br

1 Uma versão preliminar desse artigo foi apresentada no GT Comunicação em Contextos Organizacionais, no XXI Encontro da Compós, em 2012. O texto foi revisto e ampliado. 


\title{
Resumo
}

Este artigo objetiva identificar as representações sociais da responsabilidade social na publicidade institucional de um banco brasileiro e no discurso de seus funcionários e clientes. Tendo como referência a teoria das representações sociais, identificamos as representações em comerciais institucionais para televisão por meio do método semiótico e aplicamos um survey em uma amostra de 640 funcionários e 377 estudantes-clientes. Os resultados mostram distintas representações. A veiculada pela empresa busca legitimar seus interesses. Os funcionários elaboram representações de modo identitário e próximo ao discurso oficial. Os clientes representam de acordo com a sua condição de consumidores Essas representações dialogam com a representação hegemônica do capitalismo.

\section{PALAVRAS-CHAVE: REPRESENTAÇÕES SOCIAIS • RESPONSABLIDADE SOCIAL • COMUNICAÇÃO ORGANIZACIONAL}

\begin{abstract}
This article aims at identifying the social representations of social responsibility in the institutional advertising of a Brazilian bank and the speech of its employees and clients. Taking as a reference the social representations theory: representations were identified in institutional TV ads using the semiotic method; a survey was conducted on a sample of 640 employees and 377 student clients. The results show different representations. The one conveyed by the company seeks to legitimize its interests. Employees develop representations of identity in a way that is close to the official discourse. Clients represent according to their status as consumers. These representations are in tune with the hegemonic representation of capitalism.
\end{abstract}

KEYWORDS: SOCIAL REPRESENTATIONS • SOCIAL RESPONSIBILITY • ORGANIZATIONAL COMMUNICATION

\section{Resumen}

Este artículo tiene como objetivo identificar las representaciones sociales de responsabilidad social en la publicidad institucional de un banco brasileño y en el discurso de sus funcionarios y clientes. Teniendo como referencia la teoría de las representaciones sociales (TRS), identificamos las representaciones en comerciales institucionales para la televisión, por medio del método semiótico y aplicamos una encuesta para una muestra de 640 funcionarios y 377 estudiantes/ clientes. Los resultados muestran distintas representaciones. La vehiculada por la empresa busca legitimar sus objetivos. Los funcionarios elaboran representaciones que identifican y se acercan al discurso oficial. Los clientes se representan de acuerdo con su condición de consumidores. Estas representaciones dialogan con la representación hegemónica del capitalismo.

PALABRAS CLAVES: REPRESENTACIONES SOCIALES • RESPONSABILIDAD SOCIAL • COMUNICACIÓN ORGANIZACIONAL 


\begin{abstract}
A s organizações na contemporaneidade são loci por excelência de constituição de representações sociais em seus processos comunicacionais, sendo extremamente relevantes para podermos conhecer as visões de mundo, as práticas, a natureza dos relacionamentos que se estabelecem nesse contexto, bem como as especificidades dos públicos com os quais as organizações se relacionam.
\end{abstract}

\title{
AS ORGANIZAÇÕES COMO UNIVERSOS DE REPRESENTAÇÕES
}

$\mathrm{Na}$ contemporaneidade, destacam-se o crescente grau de complexidade das organizações, a ampliação e diversificação de seus públicos e as rápidas mudanças no ambiente interno e externo, com fronteiras cada vez menos delineadas. Trata-se, portanto, de um meio extremamente propício à formação de representações sociais. Na teoria das representações sociais, as funções representacionais nos instrumentalizam a compreender ambientes formados por imbricadas redes de culturas e subculturas, nos quais a dimensão simbólica e prática não podem ser separadas.

Rezende e Sá (2009) destacam que, no Brasil, o campo de estudos sobre as representações sociais em organizações ainda é marcado pela incipiência, como pode ser atestado na revisão de literatura dos artigos publicados nas áreas de administração, comunicação e comunicação organizacional (Silva, 2011).

A responsabilidade social é um conceito polissêmico, multifacetado e que torna possível uma variedade de representações, principalmente quando nos referimos aos públicos das organizações. Nossa intenção é estudar a responsabilidade social como um único construto, e não em suas variadas dimensões (Silva, 2011), e daí nosso interesse em investigar as representações sociais.

As representações sociais podem ser definidas como conhecimentos e teorias do senso comum, criadas pelos indivíduos e grupos que: orientam e ajudam a nomear e definir a realidade; possibilitam tomar decisões; levam a adotar posicionamentos; são traduzidas em práticas (Jodelet, 2001). As representações são formadas a partir de um universo reificado, geralmente constituído pelo saber científico. São criadas para tornar familiar o não-familiar, associar o que causa estranhamento a conceitos que nos são familiares. Isto ocorre por meio dos processos psicossociais da objetivação e da ancoragem.

Pela objetivação, ocorre a transformação do abstrato em uma imagem concreta, ao tornar familiar o novo conhecimento. O processo de objetivação implica uma construção seletiva em que determinados elementos do objeto são excluídos, em geral quando não se adequam às visões de mundo, às normas e aos valores dos sujeitos e grupos. Além da simplificação, são acentuados determinados aspectos com o objetivo de explicar e avaliar. Já a ancoragem se dá quando o novo passa a fazer parte, mediante ajustes, de categorias pré-existentes. É o momento de 
classificar e hierarquizar o novo. E, para isso, usa-se o processo de estereotipia, ao buscar semelhanças e diferenças nos arquivos de protótipos coletivos. A ancoragem possibilita nomear os objetos e fenômenos com base no já conhecido (Moscovici, 1978).

Estudar as representações implica conhecer o seu campo comum, socialmente compartilhado (objetivação) e as diferentes tomadas de posição (ancoragens). No caso de nosso objeto, a responsabilidade social, este saber é produzido por inferências - de acordo com o grau de dispersão de informações - e representado de diferentes maneiras - de acordo com pertenças grupais, valores, experiências, valores, histórias de vida e práticas.

Dentre as diversas correntes da teoria das representações sociais, se desenvolveu a epistemologia dialógica ou dialogicidade, iniciada por Ivana Marková, que busca entender as representações como resultado de práticas dialógicas nas quais teríamos a tríade sujeito-alter-objeto. Nessa relação, o alter pode significar outro indivíduo, um grupo ou a sociedade. A proposta da dialogicidade foi inspirada por Bakhtin e outros teóricos da linguagem e da fenomenologia cujas contribuições nos permitiriam conhecer a construção de saberes numa sociedade sempre chamada a inferir sobre fatos novos e sobre os quais há constantes divergências de posições, de ideologias e de diferenciados aspectos emocionais e afetivos em relação a esses fenômenos (Palmonari, 2009).

Nos estudos contemporâneos da comunicação, criticamos as abordagens que privilegiam como única variável os emissores, os receptores ou os conteúdos das mensagens. Dessa forma, esta pesquisa é um estudo de recepção que estuda os emissores, as mensagens, os sujeitos e grupos em interações dialógicas. Trata-se de um processo psicossocial, no qual sujeitos e grupos têm um papel ativo nas significações das mensagens.

Difícil também distinguir até que ponto a representação de temas emergentes nos contextos organizacionais contemporâneos (sustentabilidade, responsabilidade social, relações de trabalho, entre outros) numa empresa possa separar-se de sua imagem, sua identidade, suas representações, suas práticas e sua cultura organizacional. Nesse sentido, uma questão importante é: como a comunicação nas organizações é capaz de ativar, recortar e dar ênfases a determinados conteúdos de modo a contribuir para a elaboração de representações sociais nos diferentes grupos sociais? Outra indagação que surge é: que tomadas de posições adotam os sujeitos e grupos em relação a essas mensagens?

Uma das estratégias passa certamente pela identificação de gêneros de discurso institucionais que expressam a posição da empresa em relação ao tema e seus desdobramentos junto aos seus públicos.

As mensagens da comunicação institucional, como parte da comunicação organizacional conformam um gênero discursivo impregnado de conteúdos ideológicos e de legitimação da ação 
das companhias. Para conhecê-lo e contrastá-lo, é preciso se debruçar sobre as "falas" dos grupos e públicos das organizacionais.

Diante do exposto, nosso objetivo nesta pesquisa foi identificar as representações sociais presentes na comunicação institucional e no discurso de funcionários e clientes de um banco brasileiro $^{2}$. A escolha desse locus justifica-se por este setor, parte da mais importante área do capitalismo, ser constituído por empresas nas quais a comunicação organizacional é altamente desenvolvida em seus diferentes níveis e públicos e com aporte considerável de recursos. A instituição do sistema financeiro - aqui denominada Banco Beta - escolhida para estudo de caso é uma das cinco maiores do país, com variados programas de responsabilidade socioambiental e premiada nacional e internacionalmente.

\section{METODOLOGIA DOS ESTUDOS EMPÍRICOS}

Dois estudos empíricos foram realizados. No primeiro, buscou-se identificar os principais conteúdos expressos, as ênfases e os recortes a respeito da responsabilidade social presentes no discurso institucional de três comerciais para a televisão. Foi utilizada a metodologia qualitativa (análise semiótica binária).

O segundo estudo teve como objetivos identificar e comparar as representações sociais da responsabilidade social no discurso de funcionários e clientes. Foi aplicado um questionário a uma amostra de conveniência de 640 funcionários do banco e 377 estudantes universitários. Os sujeitos da pesquisa responderam a questões de evocação, hábitos de mídia e escalas de atitude sobre responsabilidade social. O método usado foi quali-quantitativo, com o uso de análises de evocação e lexical, bem como análises estatísticas descritivas e inferenciais (análises fatoriais e de correlação). As análises foram feitas dos grupos clientes e funcionários e com os grupos confundidos. A idéia era conhecer as ancoragens grupais e intergrupais.

\section{Uma das faces da moeda: comerciais institucionais e representações}

Constatamos o uso recorrente nos comerciais de figuras emotivas de linguagem para expressar sentimentos de orgulho, patriotismo, pertença e confiança. Trata-se de um discurso tecido pelo texto, por trilha sonora, imagens e cores, além de temas que sensibilizam o público e legitimam o banco. O uso de recursos oníricos, artísticos, de temas retóricos legitimadores e de metáforas (Jacobson, 2010/1967; lasbeck, 2002; Halliday, 2009) objetivam as mensagens, tornando concretos os conteúdos de responsabilidade social, um conceito polissêmico e de difícil abstração, mas que os recursos de linguagem tornam possível partilhar coletivamente.

2 Para autorização da pesquisa, assinamos um termo de responsabilidade no qual nos comprometemos a não divulgar o nome da instituição financeira. 
Nas peças, destacamos a recorrência de temas como a preservação, a continuidade e a tradição. Busca-se associar o banco com a nação e destacar seu papel como agente de desenvolvimento.

A principal função da empresa, financeira e monetária, não aparece nos conteúdos dos comerciais (lasbeck, 2002). A ênfase recai sobre a expressão de tranquilidade das pessoas, nas imagens dos resultados do financiamento à agricultura, a negócios, educação, esporte e cultura. Acreditamos que essa associação não é ingênua, uma vez que a atividade bancária e o empréstimo a altos juros, muitas vezes, são associados com a usura e mal vistos. Portanto, temos um deslocamento do discurso. Temos também um deslocamento do tempo, pois o futuro apresentado pretende demonstrar a solidez do banco, além de reforçar elementos de imagem e de identidade que buscam caracterizar o banco como um agente de desenvolvimento e não apenas como um banco como os outros.

A qual gênero de discurso/sistema de comunicação podemos associar essas mensagens publicitárias? O gênero que mais se aproxima é o da propagação que ancora o conteúdo das mensagens na cultura e na identidade do Banco Beta. Os comerciais, portanto, fazem parte de um universo simbólico no qual, associados a outros instrumentos de comunicação e estratégias de marketing, buscam construir a imagem do banco e legitimá-lo junto aos grupos sociais.

Os conteúdos de responsabilidade social aparecem conjuntamente com imagens e textos que reforçam a identidade do banco. Constatamos a tendência de incorporar um tema novo a um discurso tradicional sobre a organização.

Esse gênero de discurso revela que a responsabilidade social no banco é recortada em temas como ética, diversidade, sustentabilidade social e ambiental, que se inserem no arcabouço dos elementos retóricos legitimadores de transcendência e utilidade (Halliday, 2009). Cabem então as perguntas: de que modo a esfera ideológica está presente nesse gênero de discurso? Ela é capaz de modular as representações dos públicos?

É preciso levar em conta as características intrínsecas de nossa organização/o emissor. Trata-se de um tipo de empresa fundamental no capitalismo e, como tal, para que suporte as crescentes pressões de governos e atores sociais, é fundamental que busque, segundo a lógica do sistema, legitimar seus interesses por meio de estratégias, num processo que poderíamos denominar institucionalização de novas ideias e práticas (Cruvinel, 2008).

Daí a importância de examinarmos seus gêneros discursivos/sistemas de comunicação. A compreensão da natureza desse gênero discursivo se torna uma tarefa mais fácil quando adotamos a noção de ideologia proposta por Bakhtin, na qual todo signo é ideológico. Concebe-se a ideologia como todas as formas possíveis de interpretação da realidade social pelos indivíduos e que se expressa por meio de signos, não sendo caracterizada como um pensamento de mão única e dominante (Miotello, 2010). 
Ao analisarmos as mensagens tratamos do nível societal de ancoragem - que lida com sistema de crenças, sistemas normativos, produções culturais e ideológicas de uma sociedade ou de um grupo que dão sentido a comportamentos e tomadas de posição (Doise, 2001) e não das formas grupais e intergrupais. A partir desse ponto, é necessário saber como esse gênero de discurso dialoga com outros discursos produzidos pelos grupos sociais.

\section{Mais faces da moeda? Receptores e suas representações}

Após um teste de livre associação em que os respondentes citavam e enumeravam as palavras que Ihes vinham à mente quando pensavam na responsabilidade social do Banco Beta, a pergunta a seguir solicitava que justificassem a escolha da palavra mais importante (Figura 1).

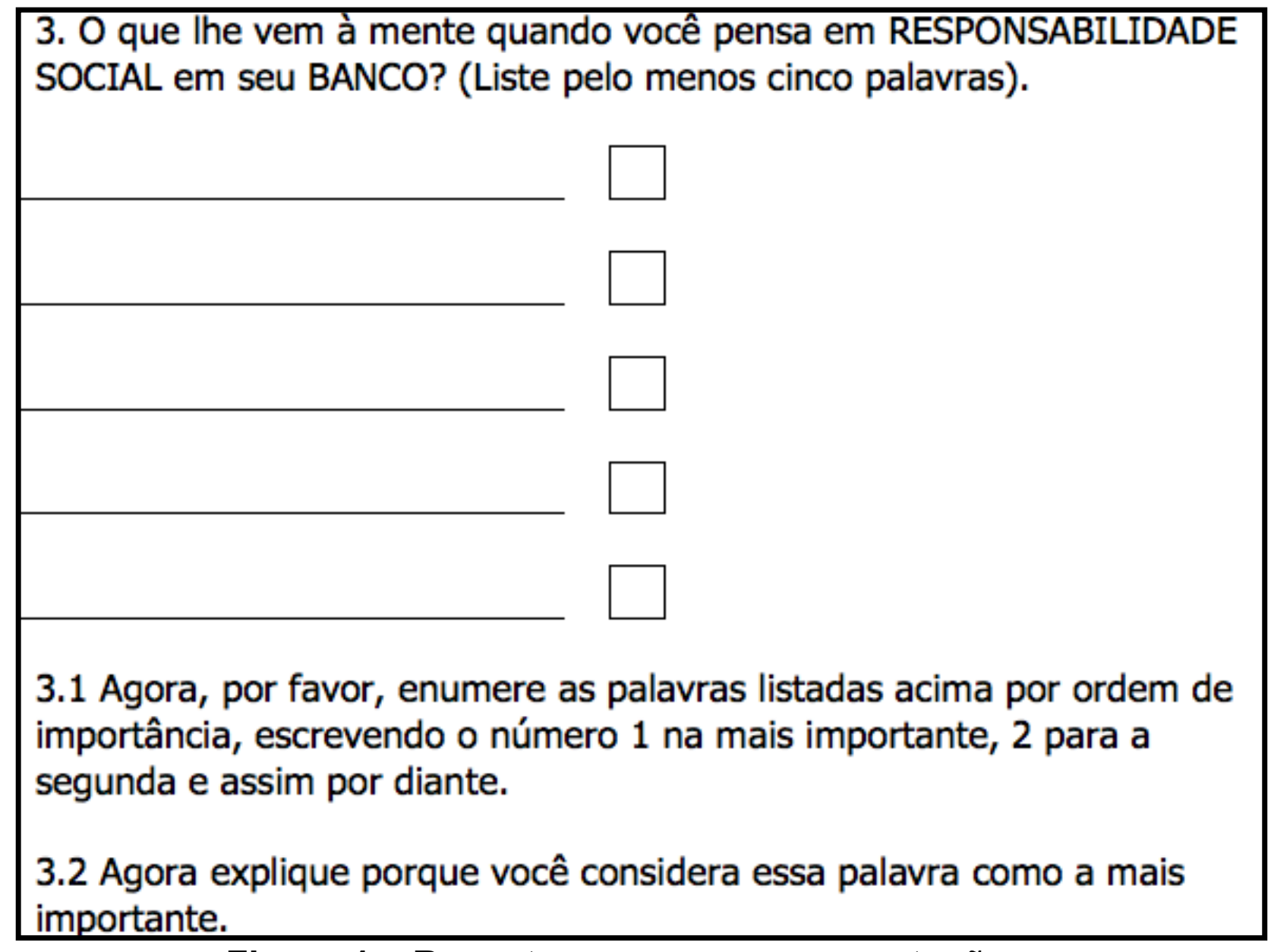

Figura 1 - Receptores e suas representações.

As respostas foram analisadas no Alceste - que classifica estatisticamente os enunciados por meio do qui-quadrado das palavras e identifica os vocabulários mais característicos de um texto. As respostas nos permitem identificar os processos de objetivação, o chamado campo comum representacional de clientes e funcionários. Todas as respostas deram origem ao dendrograma a seguir, que identifica quatro classes de enunciados (Figura 2): 


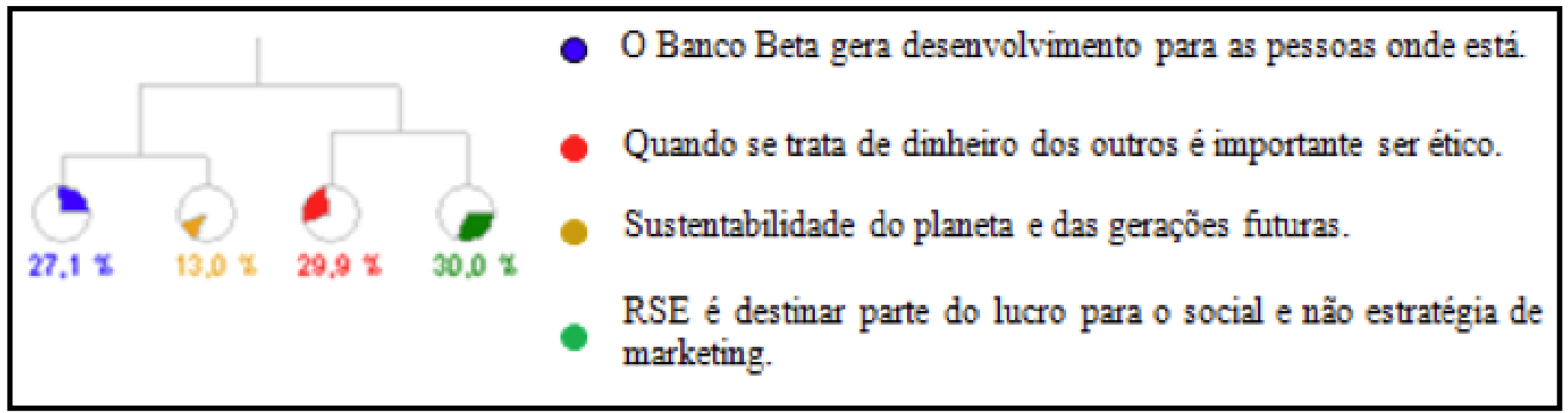

Figura 2 - Dendrograma das evocações.

Os resultados das análises lexicais e da análise fatorial mostram que estamos diante de representações essencialmente distintas divididas em dois grandes eixos que polarizam os dois grupos. No primeiro eixo, denominado "O que é a responsabilidade social no Banco Beta", os clientes afirmam que a "responsabilidade social é destinar parte do lucro para o social e não estratégia de marketing". Já para os funcionários, que é promover "a sustentabilidade do planeta e das gerações futuras".

No segundo eixo, denominado "Para quem é a responsabilidade social no Banco Beta", os clientes respondem que "quando se trata do dinheiro dos outros é importante ser ético" e os funcionários, por sua vez, afirmam "o Banco Beta gera desenvolvimento para as pessoas onde está". O grupo de funcionários objetiva e ancora suas representações nos valores da cultura organizacional com conteúdos bastante próximos ao universo reificado da responsabilidade social disseminado pelas ciências de administração e ambientais. Os clientes têm pouca intimidade com o objeto representacional e, assim, objetivam a representação em conformidade com a sua condição de consumidores e clientes.

Podemos dizer que a teoria de senso comum, criada pelos clientes para explicar o objeto, é tautológica, sem muita familiaridade com o objeto. Novamente, vemos aqui a ideia de responsabilidade social empresarial voltada para projetos e ações sociais. A noção de "agente de desenvolvimento", tão recorrente entre os bancários, é ausente da lógica dos clientes.

Os clientes-universitários de nossa pesquisa possuem uma concepção que poderíamos rotular de "autocentrada" em relação ao conhecimento que elaboram, são os usuários da responsabilidade social e não se implicam agentes. O processo de objetivação é desenvolvido a partir de seus interesses, donde a importância de o banco ser "honesto, transparente e ético", porque sua relação com o banco é a de consumidor de bens e serviços. Podemos observar aqui a seletividade e esquematização de conteúdos que se operam nesse processo de atribuir uma imagem a um conceito, de objetivar (Moscovici, 2003).

A categoria de "ser cliente" é destacada como a mais importante pelo grupo, contaminando a noção de responsabilidade social. Podemos também inferir que, para a formação de uma mesma representação, contribuem diversos universos reificados que estão ligados, nesse caso bastante vinculados aos códigos de direitos e movimentos de defesa do consumidor. 
Lembramos que a prática das empresas no setor financeiro deixa muito a desejar no respeito aos direitos dos consumidores e que elas estão entre as companhias que mais recebem reclamações em órgãos como o Procon, disputando a primazia do primeiro lugar com as empresas dos setor de telefonia e saúde (Idec, 2008).

Nos resultados da pesquisa do Idec (2008) com os oito maiores bancos do país, o Banco Beta, numa escala de 0 a 5 , recebe a nota 2,21 no tema consumidores.

Passemos agora a associar a objetivação dos clientes aos recursos de retórica utilizados pelos bancos em suas mensagens institucionais e também reforçados por sua publicidade. As empresas buscam estar afinadas em seus discursos aos valores e interesses de seus clientes (Halliday, 2009). Procuram também apresentar-se como sólidas, seguras e honestas (lasbeck, 2002), como faz o Banco Beta, ao divulgar a tradição de estar há muitos anos no mercado. Relacionamos também ao fato que os bancos são, em geral, apresentados na publicidade como "o banco que mima", " que é feito para você", " um banco todo seu" e "24 horas" - em outras palavras, dizem que estão sempre a serviço.

No discurso do grupo de funcionários há fluência verbal e uma maior lógica para falar do objeto, além de eles utilizarem um vocabulário mais rico. Marcam a noção de sustentabilidade e a explicam. Seu vocabulário revela uma maior familiaridade com o objeto de representação e também com o universo reificado. Para eles, a responsabilidade social se expande para todos os setores sociais e possibilita a qualidade de vida dos funcionários. Ela se constitui na inserção do banco nas diferentes regiões do país como agente de desenvolvimento. Os funcionários se colocam também como promotores dessa responsabilidade, já que não se dissociam do banco em seu discurso. Podemos observar, no discurso dos bancários, um sentimento de pertença e de identidade (função da representação social) em relação à organização em que trabalham é também um discurso pouco crítico em relação à responsabilidade social.

Desse modo, entendemos que os elementos dessas mensagens também estão presentes na objetivação dos bancários. Isso não quer dizer que exista uma relação de causa e efeito, mas que sinalizam a comunalidade de elementos do campo comum dessa representação e que se verificam na objetivação e na seletividade de conteúdos pelos dois grupos.

Passemos agora as análises das escalas (Figura 3), que foram elaboradas de acordo com os sete indicadores/temas de responsabilidade social definidos pelo Instituto Ethos (2009): 1. Valores, transparência e governança; 2. Público interno; 3. Meio ambiente; 4. Consumidores e clientes; 5 . Comunidade; 6 . Fornecedores; 7 . Governo e sociedade. Os temas eram sumarizados e os respondentes eram convidados a responder sobre seu nível de concordância em relação ao indicador: qual o grau de responsabilidade dos agentes sociais em relação ao indicador; qual a sua percepção do respeito do banco aos indicadores. 
O Instituto Ethos de Responsabilidade Social estabelecen 7 indicadores para considerar uma empresa socialmente responsável. Gostariamos de saber sua opinião sobre estes indicadores.

Indicador 1. Valores, Transparência e Governança

Valores e principios éticos formam a base da cultura de uma empresa, ocientando sua conduta e fundamentando sua missão social. A empresa deve buscar promover de modo transparente o dílogo, a participação e o monitoramento de suas ações por seus públicos e partes interessadas. Gera beneficios para todos com os quais interage, para a sociedade e o meio ambiente.

1. Responda em que medida você concorda com esse indicador.

Para responder faça $\mathrm{um} \mathrm{X}$ sobre um dos números. Se, você marcar os números à direita significa que: $4=$ concorda completamente; 3 = concorda mnito; $2=$ concorda; 1 = concorda pouco. Se, você marcar os números à esquerda significa que: $-4=$ discorda completamente; $-3=$ discorda muito; $-2=$ discorda; $-1=$ discorda pouco.

Marque o número 0 apenas quando você não puder se decidir

$$
\begin{aligned}
& \text { Discordo } \\
& \text { completamente }
\end{aligned} \begin{array}{|l|l|l|l|l|l|l|l|l}
-4 & -3 & -2 & -1 & 0 & 1 & 2 & 3 & 4
\end{array} \begin{aligned}
& \text { Concordo } \\
& \text { completamente }
\end{aligned}
$$

2. Seguindo a mesma lógica da questão número 1 , para fazer respeitar esse indicador, aponte o grau de responsabilidade de cada um dos seguintes agentes:

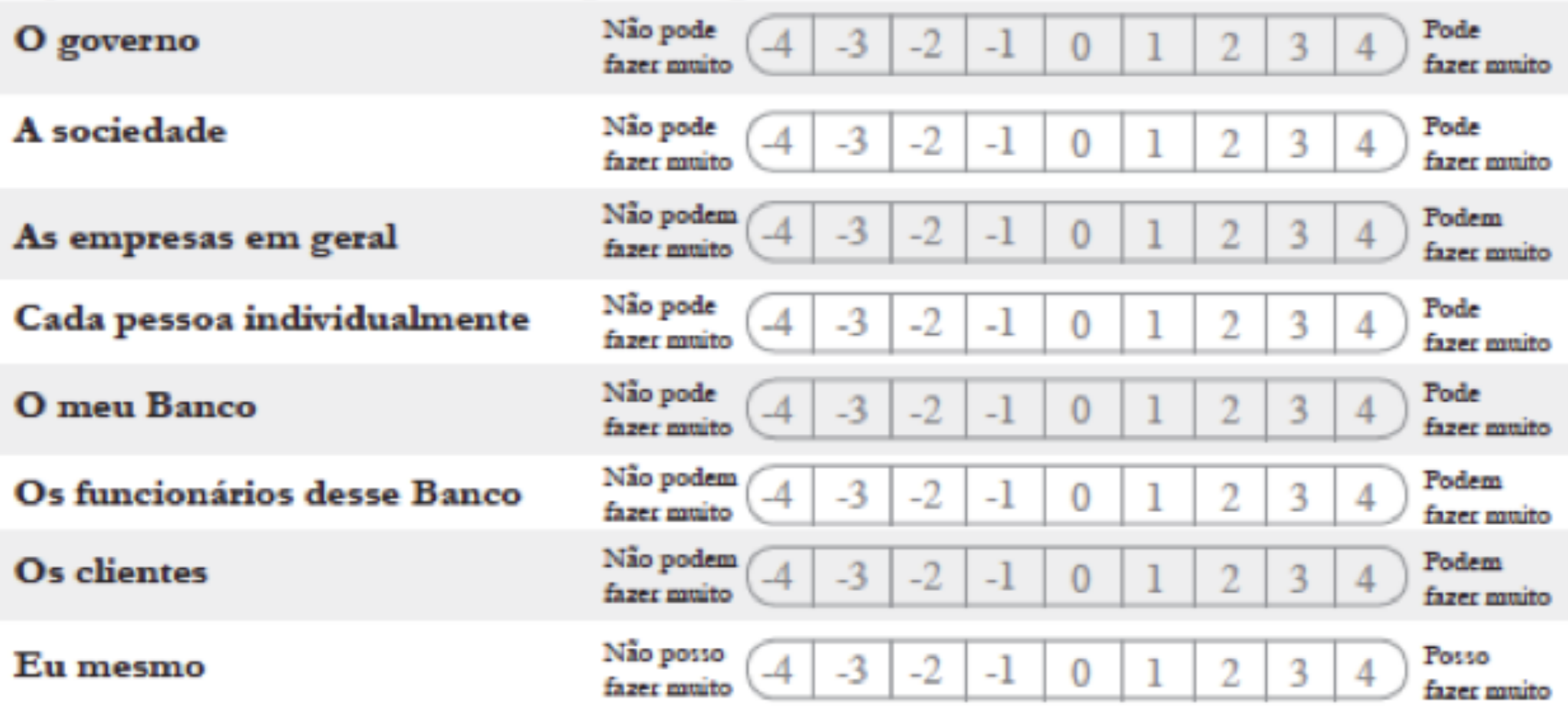

3. Avalie o quanto esse indicador é respeitado em seu $B$ anco. Marque um $\mathrm{X}$ no número de sua resposta. Se, você marcar os números à direita significa que: $4=$ respeita totalmente; 3 = respeita muito; 2 = respeita;

1 = respeita ponco; -1 = desrespeita ponco; -2 = desrespeita; -3 = desrespeita mnito; $-4=$ desrespeita totalmente.

Descespeits
totalmeate \begin{tabular}{r|l|l|l|l|l|l|l|l|}
-4 & -3 & -2 & -1 & 0 & 1 & 2 & 3 & 4 \\
\hline
\end{tabular}

Figura 3 - Escalas de concordância, agentes sociais e respeito aos indicadores sociais. As escalas foram validadas por procedimentos estatísticos e apresentaram: estrutura unifatorial, KMO acima de 0,87; índice de Bartlett $p<0,001$; e 0 alfa de Cronbach superior a 0,86 .

Os clientes-universitários dão altas notas para os indicadores de responsabilidade social, para os agentes e para o respeito dos indicadores pelo banco. Os funcionários dão notas sempre maiores que os universitários (Tabela 1). Isso pode indicar que os bancários têm maior proximidade com o objeto, pela pertença à organização. Outra possível razão seria a de que a empresa tenha conseguido disseminar internamente os conceitos, os valores e as práticas da responsabilidade social, o que implica valores mais altos de concordância, atribuição de responsabilidades e de respeito aos indicadores de responsabilidade social. 
Tabela 1 - Comparação de indicadores entre clientes-universitários e funcionários

\begin{tabular}{|c|c|c|c|c|c|c|c|c|}
\hline \multirow[t]{2}{*}{$\begin{array}{l}\text { Bancários e } \\
\text { estudantes }\end{array}$} & \multicolumn{2}{|c|}{ Geral } & \multicolumn{2}{|c|}{$\begin{array}{c}\text { Clientes- } \\
\text { universitários }\end{array}$} & \multicolumn{2}{|c|}{ Funcionários } & \multirow{2}{*}{$\mathrm{t}$} & \multirow{2}{*}{$d f$} \\
\hline & Média & $\begin{array}{l}\text { Desvio } \\
\text { Padrão }\end{array}$ & Média & $\begin{array}{l}\text { Desvio } \\
\text { padrão }\end{array}$ & $\begin{array}{l}\text { Mé- } \\
\text { dia }\end{array}$ & $\begin{array}{l}\text { Desvio } \\
\text { padrão }\end{array}$ & & \\
\hline $\begin{array}{c}\text { Concordância } \\
\text { Média }\end{array}$ & 7,85 & 1,09 & 7,51 & 1,26 & 8,06 & 0,91 & $-6,445^{*}$ & 479 \\
\hline $\begin{array}{l}\text { Sociedade } \\
\text { Média }\end{array}$ & 7,74 & 1,19 & 7,54 & 1,26 & 7,85 & 1,13 & $-3,612^{*}$ & 594 \\
\hline Empresa Média & 7,91 & 1,21 & 7,69 & 1,28 & 8,05 & 1,14 & $-3,999^{*}$ & 590 \\
\hline $\begin{array}{c}\text { Meu Banco } \\
\text { Média }\end{array}$ & 8,08 & 1,08 & 7,65 & 1,27 & 8,34 & 0,84 & $-8,551^{*}$ & 474 \\
\hline $\begin{array}{c}\text { Cada pessoa } \\
\text { Média }\end{array}$ & 7,46 & 1,23 & 7,11 & 1,24 & 7,66 & 1,18 & $-6,373^{*}$ & 827 \\
\hline $\begin{array}{c}\text { Funcionários } \\
\text { Média }\end{array}$ & 7,68 & 1,14 & 7,14 & 1,23 & 8,00 & 0,95 & $-10,655^{*}$ & 527 \\
\hline Cliente Média & 7,35 & 1,27 & 6,98 & 1,28 & 7,58 & 1,21 & $-6,716^{*}$ & 827 \\
\hline $\begin{array}{c}\text { Eu mesmo } \\
\text { Média }\end{array}$ & 7,61 & 1,20 & 7,03 & 1,31 & 7,96 & 0,98 & $-10,827^{*}$ & 514 \\
\hline Respeito Média & 7,34 & 1,13 & 6,67 & 1,15 & 7,76 & 0,90 & $-13,638^{*}$ & 499 \\
\hline
\end{tabular}

*Nível de significância inferior 0,05.

Foram encontradas correlações estatísticas significativas entre as maiores notas dadas aos indicadores de responsabilidade social do banco nas três escalas e na variável "acreditar nos comerciais institucionais". Em outras palavras, quando os sujeitos acreditam nas propagandas, o banco é mais bem avaliado em relação às suas ações de responsabilidade social. Isso acontece tanto nos grupos confundidos quanto nos grupos em separado.

Em relação à escala de responsabilidade, acontece uma gradação nas notas atribuídas aos agentes sociais (maior nota para o banco e para a empresa e menor para os clientes e "eu mesmo") . Decidimos aqui fazer uma comparação com os grupos confundidos. No cruzamento efetuado, a variável "acreditar na propaganda" foi correlacionada significativamente em relação à média atribuída à responsabilidade dos agentes sociais.

Na comparação geral entre clientes e funcionários, no tocante à responsabilidade dos agentes sociais, as médias decrescem até chegar aos clientes. Isso contraria o discurso quanto ao poder do consumidor sobre as empresas como sendo um dos principais stakeholders a pressionar as companhias para a adoção de práticas socialmente responsáveis. Entretanto, confirma os resultados da pesquisa Instituto Akatu/Instituto Ethos (Akatu/Ethos, 2010) sobre as percepções do 
consumidor brasileiro em relação à responsabilidade social empresarial. Essa pesquisa, realizada em 2006-2007, revela que os consumidores nacionais têm uma visão positiva em relação à responsabilidade social empresarial, sabem que têm poder de influência sobre as companhias e esperam que o governo regulamente essas ações. Apesar disso, são pouco ativos e não desenvolvem, prestigiam ou até boicotam as corporações em razão de suas práticas de responsabilidade.

Resultados dos grupos em separado e confundidos nos fazem inferir que estamos também diante de uma representação hegemônica em relação à Responsabilidade social empresarial. Nessa representação a empresa é a principal protagonista, restando aos consumidores e indivíduos uma menor responsabilização. Segundo Valla (2006) as representações hegemônicas estão associadas à propagação. As representações hegemônicas têm por função regular os dogmas tradicionais nos grupos, são intimamente reguladas por esse sistema de comunicação que tem por finalidade "vigiar a manutenção de representações existentes, e integrar as novas representações num quadro de pensamento que não afete as primeiras" (Valla, 2006, p. 477). As representações hegemônicas são exitosas nessa tarefa não porque têm algum poder de coerção, mas por seus conteúdos e a maneira como são disseminados. Desse modo, são capazes de pautar temas novos com base no antigo. Acreditamos que seja justamente isso que as empresas fazem quando se comunicam com seus públicos sobre a responsabilidade social.

Essas representações relacionam-se à representação hegemônica da responsabilidade social empresarial, que atribui às empresas a função de legitimação do capitalismo e um papel, ao mesmo tempo, protagonista e alienante.

O estudo mostra com clareza as discrepâncias entre os discursos da empresa e a recepção junto aos públicos e como os valores, status social e sentimentos de pertença e identidade influenciam na atribuição de sentidos das mensagens.

\section{CONSIDERAÇÕES FINAIS}

Nosso objetivo foi identificar as representações sociais presentes na publicidade institucional e no discurso de funcionários e clientes do Banco Beta. Percebemos representações distintas. $O$ estudo de recepção que empreendemos desenvolveu-se no bojo dos processos representacionais (objetivação e ancoragem).

Nos comerciais institucionais, observamos, principalmente, a objetivação da representação. Verificamos uma seletividade de conteúdos e o uso de metáforas que reforçam a analogia do Banco Beta com o país. Há uso recorrente dos recursos retóricos legitimadores e ressignificação do papel desse agente financeiro por meio do destaque de atributos como a segurança, a solidez e a tradição. 
No estudo quantitativo, por meio da análise da objetivação, constatamos que os clientes têm menos domínio, as representações sociais estão circunscritas à sua posição de clientes do banco. Eles também demonstram maior ceticismo, assim como tendem a reduzir e a vincular a responsabilidade social do banco a ações sociais.

No grupo dos funcionários, identificamos que o modo como objetivam o objeto revela bastante intimidade e domínio, o que torna a "teoria" desse grupo mais elaborada e bastante relacionada à discussão sobre a sustentabilidade. Além disso, mostramos que essa representação se ancora na cultura, nos valores e na identidade da empresa. Ela gera mecanismos de identificação nesse grupo que, muitas vezes, os colocam quase como porta-vozes da organização.

$\mathrm{Na}$ ancoragem acessada por meio das escalas, clientes e funcionários atribuem valores de muita concordância às ações de responsabilidade social do Banco Beta. Entretanto, se sentem menos implicados sendo responsáveis pela responsabilidade social.

Em relação à ancoragem dos dois grupos, acreditar na publicidade dos bancos implica dar notas maiores na escala de responsabilidade corporativa e de concordância, responsabilidade e respeito. As análises em relação à publicidade sugerem que clientes e funcionários aderem a princípios de tomadas de posição que foram expressos nos anúncios.

Agora, retomamos o argumento de legitimação da ação das empresas por meio da responsabilidade social. $\mathrm{O}$ discurso empresarial, compartilhado pelos principais bancos, coloca a empresa como principal protagonista de um modelo no qual esta assume e até mesmo extrapola as funções do estado. Esse discurso é legitimado pela centralidade das empresas no capitalismo e na promoção da sustentabilidade.

O discurso empresarial que coloca as companhias como protagonistas desse processo, na fala com seus públicos os coloca numa posição alienante e passiva. Trata-se de um discurso atomizante, porque desconsidera um papel mais amplo e participativo que os indivíduos e grupos poderiam ter na promoção da responsabilidade social.

Apesar das limitações, consideramos que esta pesquisa traz importantes contribuições para que possamos compreender, com maior profundidade, os processos de recepção e a função das representações nos contextos organizacionais. O nível organizacional configura-se como um promissor nível de análise no estudo da ancoragem e de seus processos. E, considerado esse âmbito, uma dimensão fundamental a ser analisada é a da comunicação nas organizações apreendida em dialogicidade com os discursos sociais. 


\section{REFERÊNCIAS}

CRUVINEL, Elvira. Responsabilidade social em instituições financeiras: a institucionalização da prática dos bancos no Brasil. Rio de Janeiro: Elsevier, 2008.

DOISE, Willem. Atitudes e representações. In: JODELET, Denise (Org.). As representações sociais. Rio de Janeiro: Eduerj: 2001.

ETHOS. Instituto Ethos de Responsabilidade Social. Disponível em: <http://www.ethos.org.br/DesktopDefault.aspx?Tabl$\mathrm{D}=4206$ \&Alias=ethos \& Lang=pt-BR $>$. Acesso em: 20/04/2009.

HALLIDAY, Tereza Lúcia. Discurso organizacional: uma abordagem retórica. In: KUNSCH, Margarida M. Krohling (Org.). Comunicação organizacional. Vol. 2. Linguagem, gestão e perspectivas. São Paulo: Saraiva, 2009.

IDEC - Instituto de Defesa do Consumidor. Avaliação comparativa da responsabilidade socioambiental dos bancos no Brasil - versão final. São Paulo: Idec, 2008.

IASBECK, Luis Carlos Assis. A arte dos slogans: as técnicas de construção das frases de efeito no texto publicitário. Brasília: Annablume / UPIS, 2002.

AKATU; ETHOS. 2010. Responsabilidade social das empresas: percepção do consumidor brasileiro - Pesquisa $2006-2007$. Sumário de Conclusões. São Paulo: Instituto Akatu e Instituto Ethos de Responsabilidade Social. Disponível em:<http:// www.akatu.org.br/akatu_acao/publicacoes/responsabilidadesocialempresarial>. Acesso em: 03/01/2010,

JACOBSON, Roman. Linguística e comunicação. São Paulo: Cultrix, 2010.

JODELET, Denise. Representações sociais: um domínio em expansão. In: JODELET, Denise (Org.). As representações sociais. Rio de Janeiro: Eduerj, 2001.

MIOTELLO, Valdemir. Ideologia. In: BRAIT, Beth (Org.). Bakhtin: conceitos-chave. São Paulo: Editora Contexto, 2010.

MOSCOVICl, Serge. A representação social da psicanálise. Rio de Janeiro: Zahar, 1978.

Representações sociais: investigações em psicologia social. Petropólis (RJ): Vozes, 2003.

PALMONARI, Augusto. A importância das representações para a psicologia social. In: Almeida, Angela M. O.; JODELET, Denise (Org.). Interdisciplinaridade e diversidade de paradigmas. Brasília: Thesaurus, 2009.

REZENDE, Izabela T. Maria; SÁ, Celso Pereira. Teoria das representações sociais, organizações e trabalho: o que tem sido pesquisado e publicado no âmbito nacional e internacional? In: CONFERÊNCIA BRASILEIRA DE REPRESENTAÇÕES SOCIAIS, IV, Rio de Janeiro, 2009. Anais... Resumo completo publicado, Eduerj, 2009.

SILVA, Luiza Mônica Assis da. Várias faces de uma mesma moeda: representações da responsabilidade social em um banco público brasileiro. 2011. Tese (Doutorado em Psicologia Social, do Trabalho e das Organizações) - Universidade de Brasília, Brasília, 2011.

VALLA, Jorge. Representações sociais e psicologia do conhecimento cotidiano. In: VALA, Jorge; MONTEIRO, Maria Benedicta. (Org.). Psicologia social. Lisboa: Editora Fundação Calouste Gulbekian, 2006. 